\title{
Adherence to Mediterranean diet and risk of developing diabetes: prospective cohort study
}

\author{
MÁ Martínez-González, professor of epidemiology and chair, ${ }^{1}$ C de la Fuente-Arrillaga, research assistant, ${ }^{1}$ \\ J M Nunez-Cordoba, research fellow, ${ }^{1,2}$ F J Basterra-Gortari, research fellow, ${ }^{1,3}$ | J Beunza, assistant \\ professor, ${ }^{1}$ Z Vazquez, research assistant, ${ }^{1}$ S Benito, research assistant, ${ }^{1}$ A Tortosa, research fellow, ${ }^{1}$ \\ M Bes-Rastrollo, assistant professor ${ }^{1}$
}

\begin{abstract}
'Department of Preventive Medicine and Public Health, Medical School-Clinica Universitaria, University of Navarra, Pamplona, Spain ${ }^{2}$ Department of Preventive Medicine and Quality Management, Hospital Virgen del Camino, Pamplona, Spain

${ }^{3}$ Department of Endocrinology, Hospital of Navarra, Pamplona, Spain

Correspondence to: M Á MartínezGonzález mamartinez@unav.es
\end{abstract}

doi:10.1136/bmj.39561.501007.BE

\section{ABSTRACT}

Objective To assess the relation between adherence to a Mediterranean diet and the incidence of diabetes among initially healthy participants.

Design Prospective cohort study with estimates of relative risk adjusted for sex, age, years of university education, total energy intake, body mass index, physical activity, sedentary habits, smoking, family history of diabetes, and personal history of hypertension.

Setting Spanish university department.

Participants 13380 Spanish university graduates without diabetes at baseline followed up for a median of 4.4 years.

Main outcome measures Dietary habits assessed at baseline with a validated 136 item food frequency questionnaire and scored on a nine point index. New cases of diabetes confirmed through medical reports and an additional detailed questionnaire posted to those who self reported a new diagnosis of diabetes by a doctor during follow-up. Confirmed cases of type 2 diabetes. Results Participants who adhered closely to a Mediterranean diet had a lower risk of diabetes. The incidence rate ratios adjusted for sex and age were 0.41 ( $95 \%$ confidence interval 0.19 to 0.87 ) for those with moderate adherence (score 3-6) and 0.17 (0.04 to 0.75) for those with the highest adherence (score 7-9) compared with those with low adherence (score $<3$ ). In the fully adjusted analyses the results were similar. A two point increase in the score was associated with a $35 \%$ relative reduction in the risk of diabetes (incidence rate ratio 0.65 , 0.44 to 0.95$)$, with a significant inverse linear trend $(P=0.04)$ in the multivariate analysis.

Conclusion Adherence to a Mediterranean diet is associated with a reduced risk of diabetes.

\section{INTRODUCTION}

Diabetes mellitus is an increasingly important global public health problem that threatens to reach pandemic levels by 2030. ${ }^{12}$ As some randomised trials have consistently shown, increased physical activity and weight loss are efficient approaches for the control and prevention of type 2 diabetes. ${ }^{34}$ Diet has also long been believed to be an important risk factor for diabetes. Many studies have shown that the Mediterranean food pattern has a role in prevention of cardiovascular disease..$^{5-9}$ The similarity of some risk factors and some empirical and mechanistic evidence suggest that the Mediterranean diet can also protect against diabetes. The major protective characteristics include a high intake of fibre, a high intake of vegetable fat, a low intake of trans fatty acids, and a moderate intake of alcohol. ${ }^{41011}$ Moreover, a particular feature of the diet is the abundant use of virgin olive oil for cooking, frying, spreading on bread, or dressing salads. ${ }^{12}$ This leads to a high ratio of monounsaturated fatty acids to saturated fatty acids. This ratio can be used to score adherence to a Mediterranean $\operatorname{diet}^{8}$ as the traditional diet. Despite having a relatively high total fat content, this food pattern is rich in monounsaturated fatty acids (from olive oil) and poor in saturated fatty acids. Diets rich in monounsaturated fatty acids improve lipid profiles and glycaemic control in people with diabetes, suggesting that a high intake improves insulin sensitivity. ${ }^{13-16}$ Together these associations suggest the hypothesis that following an overall pattern of Mediterranean diet can protect against diabetes. In addition to having a long tradition of use without evidence of harm, a Mediterranean diet is highly palatable, and people are likely to comply with it. $^{17}$

Few prospective studies have evaluated the specific role of the Mediterranean diet on the risk of developing diabetes in initially healthy Mediterranean populations. A prospective follow-up study recently reported an inverse association between adherence to the diet and the incidence of diabetes. ${ }^{18}$ All members of that study, however, had survived a previous myocardial infarction and the tool to assess dietary habits had inherent limitations because it included only a short list of items, and the authors did not attempt to measure the entire diet.

We evaluated the association between adherence to a Mediterranean diet and the incidence of diabetes using a full validated food frequency questionnaire to measure the entire diet. 


\section{METHODS}

\section{Study population}

The objectives, design, and methods of the SUN project ("Seguimiento Universidad de Navarra" (University of Navarra follow-up) have been described elsewhere.${ }^{1920}$ Briefly, we invited all former students of the University of Navarra, registered nurses from Spanish provinces, and university graduates from other associations to take part in the project. We posted them a questionnaire and an invitation letter to participate in a long term follow-up study. The first participants were recruited in December 1999. Using successive waves of invitation to different groups of university graduates, we have increased the sample size of the cohort. The design is that of a dynamic cohort and the recruitement is permanently open. We considered a response to the initial questionnaire as informed consent to participate in the study.

After the baseline assessment, every two years we send participants follow-up questionnaires on diet, lifestyle, risk factors, and medical conditions. ${ }^{20}$ Participants who do not reply to the follow-up questionnaires are sent up to five additional mailings. Participants are aged 20-90 years at baseline.

Up to November 2007, the project had enrolled 18700 participants. From these, 15970 were eligible for follow-up because they had taken part for more than two years and had completed the follow-up process (entering the cohort up to March 2005), of whom $13753(86.1 \%)$ had completed at least their two year follow-up questionnaire. Among them, 9298 participants who had taken part for more than four years had completed at least the four year follow-up questionnaire and 4993 had completed the six year follow-up questionnaire. For this analysis, we excluded participants who had diabetes at baseline and those who reported a baseline history of cardiovascular disease. This left 13380 for analyses.

\section{Dietary assessment}

We assessed dietary habits at baseline using a semiquantitative food frequency questionnaire with 136 items, previously validated in Spain. ${ }^{21}$ In the validation study, the correlation coefficients between the questionnaire and diet records ranged from 0.45 for vitamin A to 0.91 for alcohol. ${ }^{21}$ With regard to gross misclassification, on average $3 \%$ of participants classified in the highest or lowest fifth of the distribution by food record were assigned to the lowest or highest fifth by the food frequency questionnaire. ${ }^{21}$ The questionnaire was based on typical portion sizes and had nine options for the frequency of intake in the previous year for each food item (ranging from never or almost never to six or more times a day). We used the sum of the consumption of each of several food items to estimate the overall consumption of the food group to which each item belonged (vegetables, fruits, cereals, legumes, fish, meats, fast food, dairy products). We applied the specified portion sizes for each item and summed up across all foods of that group. Then we computed the mean for all the participants in each category of the three categories of the score to create an estimated daily intake.

Nutrient intake scores were computed with a specifically developed computer program. A trained dietitian updated the nutrient data bank using the latest available information included in food composition tables for Spain. The questionnaire included questions on use of fats and oils, cooking methods, and dietary supplements. For example, we calculated total consumption of olive oil (a major source of monounsaturated fat in this population) from the nutrient score of olive oil consumption, taking into account the amount and type of olive oil used for cooking or frying and the use of olive oil for salad dressing or as a spread on bread or other foods.

Adherence to the Mediterranean diet was appraised according to the score created by Trichopoulou et al, ${ }^{22}$ which is extensively used because it is simple and has variants created to evaluate multiple diet-health relations. ${ }^{23}$ Originally, this index included only eight components to define the Mediterranean $\operatorname{diet}^{22}$ : high ratio of monounsaturated:saturated fatty acids, moderate intake of alcohol, high intake of legumes, high intake of grains, high intake of fruit and nuts, high intake of vegetables, low intake of meat and meat products, and moderate intake of milk and dairy products. The same authors subsequently added high intake of fish. ${ }^{8}$ The index assigns a score of 0 or 1 according to the daily intake of each of the nine components. With the exception of alcohol, the sex specific medians of the sample were used as cut-off points and the unit of measurement was grams per day. ${ }^{82-24}$ For each of the six protective components (fatty acid ratio, legumes, grains, fruits, vegetables, or fish) participants received one point if their intake was over the sample median. Participants received one point if the intake was below the median for the two non-protective components (dairy products or meat). For alcohol one point was scored if consumption was 10-50 g/day for men or 5-25 g/day for women. If participants met all the characteristics of the Mediterranean diet, their score was the highest (nine points), reflecting maximum adherence. If they met none of the characteristics the score was minimum (zero), reflecting no adherence at all.

\section{Assessment of other covariates}

The baseline questionnaire requested information about the main known risk factors for diabetes. We also collected information on sociodemographic factors (sex, age, university degree, and marital and employment status), anthropometric measurements (weight, height), health related habits (smoking status, physical activity, sedentary lifestyle), and clinical variables (use of medication, personal and family history of diabetes and hypertension, coronary heart disease, and other cardiovascular disease). The validity of self reported weight and body mass index (BMI) has been previously documented in a subsample of this 
cohort. ${ }^{25}$ We assessed the participation and time spent in 17 different activities, using a physical activity questionnaire previously validated in Spain. ${ }^{26}$ The time spent at each activity in hours each week was multiplied by its typical energy expenditure, expressed in metabolic equivalent tasks (METs), then summed over all activities to yield a METs-hour/week score for each participant. ${ }^{27}$

\section{Ascertainment of diabetes}

Participants reported any medical diagnosis of diabetes at baseline and in each of the follow-up questionnaires. The baseline questionnaire also collected data on use of insulin or oral antidiabetic agents. Follow-up questionnaires recorded the date of any new diagnosis of diabetes (if applicable).

Participants were considered to have diabetes at baseline if they reported a medical diagnosis of diabetes or were receiving insulin or oral antidiabetic agents. Probable cases of new onset diabetes were defined as those participants who reported a diagnosis of diabetes made by a doctor in the follow-up questionnaire and did not have diabetes at baseline. We sent additional questionnaires to participants who reported probable new onset diabetes, requesting confirmation of the diagnosis, the type of diabetes, the date of the diagnosis, whether the diabetes was diagnosed during pregnancy, the highest fasting glucose value that they ever had, whether they had ever undergone an oral glucose tolerance test and its results, their current use of insulin or oral antidiabetic agents, and the incidence of some complications. We also asked them to send us the medical report detailing the diagnosis. A panel of physicians, blinded to the information about dietary habits, used the information provided by participants (additional questionaires and medical reports) to classify the diagnosis as incident type 2 diabetes or not. The diagnosis criteria for type 2 diabetes were those of the American Diabetes Association (symptoms of diabetes plus casual plasma glucose concentration $\geq 11.1 \mathrm{mmol} / 1$ or fasting plasma glucose $\geq 7.0 \mathrm{mmol} / 1$, or two hour postload glucose $\geq 11.1 \mathrm{mmol} / 1$ during an oral glucose tolerance test; in the absence of unequivocal hyperglycaemia, confirmation by repeat testing on a different day is requested). Participants were classified as having confirmed incident type 2 diabetes only if they sent us written confirmation that the diagnosis had been received at least six months after they completed the baseline questionnaire and the diagnosis was not made during pregnancy (that is, we excluded cases of gestational diabetes).

\section{Statistical analysis}

To estimate incidence rate ratios and their 95\% confidence intervals, we ran Poisson regression models with robust standard errors, controlling simultaneously for known risk factors for diabetes: sex, age, years of university education, total energy intake, body mass index, physical activity, hours sitting down a week, family history of diabetes, baseline hypertension, and smoking. For all analyses, we considered participants with the lowest level of adherence to the Mediterranean diet $($ score $<3)$ at baseline as the reference category.

When we designed the study, taking into account the planned age and sex distribution of cohort members and the available data about incidence of diabetes in Spain, we expected an overall rate of new onset type 2 diabetes of three cases for 1000 person years of followup. Thus, in the follow-up of 12000 cohort members for an average 4.4 years we would have expected 158 new cases of type 2 diabetes and the statistical power would have been $>90 \%$ for the comparison of the two extreme quarters, assuming a relative risk of 0.5 and a two tailed $\alpha$ error of 0.05 . The statistical power for the trend test would be higher because both intermediate quarters would also be taken into account.

Because of the surprisingly low incidence of confirmed cases of diabetes, instead of using quarters, we grouped the exposure variable into only three categories. In addition to the reference category (lowest adherence, score $<3$ ), we built two other categories: moderate adherence (score 3-6) and high adherence (score 7-9). We did not use any imputation method for the missing data of participants lost to follow-up. Missing data for baseline leisure time physical activity $(5.2 \%)$, smoking $(3.6 \%)$, height $(1.0 \%)$, or weight $(0.2 \%)$ were imputed by using regression models. We treated participants with missing data for hours spent sitting down a week $(20.9 \%)$ as a separate category for this variable. We conducted tests of linear trend (likelihood ratio test) across increasing categories of the score by using the score as a continuous variable and adjusting for the potential confounders. All $\mathrm{P}$ values were two tailed, and significance was set at $\mathrm{P}<0.05$.

\section{RESULTS}

During the follow-up period (median 4.4 years), 103 participants initially free of diabetes (according to their baseline questionnaire) self reported a new diagnosis of diabetes. After we excluded 39 women who developed gestational diabetes, six cases of impaired glucose tolerance mistakenly reported by participants as diabetes, three participants with prevalent type 2 diabetes at baseline who did not report it in the baseline questionnaire, one case of incident type 1 diabetes, and 21 participants who did not send us any additional medical report, we identified 33 cases of new onset confirmed type 2 diabetes among 58918 person years of follow-up.

Table 1 shows the characteristics of the participants according to their level of adherence to the Mediterranean diet. Though participants with the highest adherence to the diet (score $>6$ ) had a higher level of leisure time physical activity, they also exhibited a higher baseline prevalence of most risk factors for diabetes because they were older, had a higher BMI, a higher total energy intake, were more likely to have 
Table 1| Baseline characteristics of 13380 participants according to adherence (Trichopoulou's score $^{22}$ ) to Mediterranean food pattern at baseline. Figures are means (SD) unless stated otherwise

\begin{tabular}{|c|c|c|c|}
\hline & $\begin{array}{c}\text { Low (score } 0-2 ; \\
n=2253 \text { ) }\end{array}$ & $\begin{array}{l}\text { Moderate (score 3- } \\
\quad 6 ; n=9604)\end{array}$ & $\begin{array}{c}\text { High (score 7-9, } \\
n=1523)\end{array}$ \\
\hline Sex (\% men) & 39.7 & 39.0 & 44.1 \\
\hline Age (years) & $33.8(9.9)$ & $37.9(11.7)$ & $42.9(12.4)$ \\
\hline Years of university education & $5.0(1.6)$ & $5.0(1.6)$ & $5.0(1.6)$ \\
\hline Body mass index $\left(\mathrm{kg} / \mathrm{m}^{2}\right)$ & $23.0(3.4)$ & $23.4(3.4)$ & $23.8(3.4)$ \\
\hline Weight (kg) & $66.2(14.4)$ & $66.9(13.9)$ & $67.8(13.3)$ \\
\hline Mean yearly weight increase $(\mathrm{kg})$ & $0.4(4.1)$ & $0.3(3.3)$ & $0.4(4.3)$ \\
\hline Physical activity (METs-h/week) & $24.1(23.4)$ & $29.3(26.2)$ & $36.4(29.2)$ \\
\hline Hours/week sitting down & $39.0(15.5)$ & $37.2(15.6)$ & $35.6(15.0)$ \\
\hline Family history of diabetes (\%) & 11.9 & 13.8 & 16.7 \\
\hline Former smokers (\%) & 22.1 & 28.8 & 37.5 \\
\hline Current smokers (\%) & 24.2 & 24.2 & 22.7 \\
\hline Hypertension at baseline (\%)* & 6.2 & 9.0 & 13.1 \\
\hline Total energy intake (MJ/day)† & $10(4)$ & $11(4)$ & $12(4)$ \\
\hline \multicolumn{4}{|c|}{ Fatty acids (\% of total caloric intake)†: } \\
\hline Saturated & $15(3)$ & $12(3)$ & $10(2)$ \\
\hline Monounsaturated & $16(3)$ & $16(4)$ & $15(4)$ \\
\hline \multicolumn{4}{|l|}{ Dietary intake (g/day)†: } \\
\hline Alcohol & $4(9)$ & $7(11)$ & $10(11)$ \\
\hline Total dietary fibre & $18(8)$ & 29 (15) & $41(18)$ \\
\hline Cereal fibre & $2(2)$ & $4(3)$ & $5(4)$ \\
\hline Olive oil & $12(11)$ & $19(17)$ & $26(18)$ \\
\hline Vegetables & 308 (189) & $547(388)$ & $773(430)$ \\
\hline Fruits & $176(153)$ & $371(347)$ & $559(408)$ \\
\hline Cereals & $77(69)$ & $113(89)$ & $150(98)$ \\
\hline Legumes & $17(14)$ & $24(24)$ & $31(38)$ \\
\hline Fish & $63(41)$ & $103(79)$ & $140(75)$ \\
\hline Meats/meat products & $199(100)$ & $187(108)$ & $154(93)$ \\
\hline Fast food $\ddagger$ & $27(25)$ & $22(28)$ & $17(34)$ \\
\hline Dairy products & $338(266)$ & $226(233)$ & 109 (133) \\
\hline
\end{tabular}

METs-h/week=metabolic equivalents of weekly leisure time physical activities.

*Medical diagnosis required.

tEstimated values, see text.

$\ddagger$ Hamburger, sausages, and pizza. point increase in the score resulted in a $35 \%$ relative reduction in the risk of developing diabetes. The multivariate adjusted inverse linear trend was significant $(\mathrm{P}=0.04)$.

\section{DISCUSSION}

This large prospective study shows that a traditional Mediterranean food pattern is associated with a significant reduction in the risk of developing type 2 diabetes.

Interestingly, among participants with the highest adherence to the diet, there was a high prevalence of important risk factors for diabetes, such as older age, higher BMI, family history of diabetes, and personal history of hypertension and a higher proportion of exsmokers. Therefore, we would have expected a higher incidence of diabetes among these participants. These higher risk participants with better adherence to the diet, however, had a lower risk of diabetes, suggesting that the diet might have a substantial potential for prevention. This finding is consistent with our previous report of an inverse association between a Mediterranean diet and the metabolic syndrome. ${ }^{24}$ The metabolic syndrome is closely associated with a generalised metabolic disorder of insulin resistance, which is one of the underlying causes of type 2 diabetes. Therefore a high biological plausibility exists to support the causality of our findings. In addition, a previous cohort study of survivors of myocardial infarction also reported that a higher adherence to a Mediterranean diet was associated with a reduction in the risk of type 2 diabetes, ${ }^{18}$ despite use of a relatively inaccurate tool for the dietary assessment. The inverse graded doseresponse pattern and the significant inverse trend that we observed also support a causal relation.

\section{Diet and disease}

Experimental evidence suggesting that a diet similar to the Mediterranean diet and rich in plant based foods might protect against diabetes can also be found in the Indian diabetes prevention programme. That trial promoted a plant based diet (together with increases in physical activity) and found a significant reduction in the incidence of diabetes,$^{28}$ although there are clear differences between the Mediterranean and Indian food patterns.

There is an analogy between coronary heart disease and diabetes because patients with type 2 diabetes and no coronary heart disease have a risk of coronary heart disease similar to patients without diabetes but with prior coronary heart disease. ${ }^{29}$ There is evidence that a Mediterranean diet protects against coronary heart disease, and the analogy between coronary heart disease and diabetes suggests that this diet might also prevent diabetes. It has been shown to provide protection against coronary mortality ${ }^{893031}$ and the incidence of non-fatal myocardial infarction. ${ }^{32}$ In addition, both cohort studies ${ }^{33-35}$ and randomised trials ${ }^{36}$ have found that adherence to a Mediterranean
When we introduced the score as a continuous variable we found that an increase of two points in the score was associated with an incidence rate ratio of 0.65 ( 0.44 to $0.95)$ in the fully adjusted model, indicating that a two 
diet protects against mortality in patients who already have established coronary heart disease.

The potential mechanisms explaining the protective effect of a Mediterranean diet on diabetes have been reviewed elsewhere. ${ }^{37-40}$ Two trials have shown that virgin olive oil protects against insulin resistance and the metabolic syndrome. ${ }^{67}$ Indexes of insulin resistance were significantly improved among participants allocated to a Mediterranean diet rich in virgin olive oil. Olive oil is rich in monounsaturated fatty acids, and a diet rich in monounsaturated fatty acids is beneficial among those with diabetes and might lead to improved insulin sensitivity and better lipid profiles than diets rich in carbohydrate. ${ }^{131539}$ People allocated to a Mediterranean diet secrete more glucagon-like peptide- $1,{ }^{16}$ a finding also seen in animals. ${ }^{14}$ The non-fat minor components of virgin olive oil also exert a beneficial effect on pro-inflammatory cytokines. ${ }^{40-42}$

Apart from olive oil, adherence to an overall Mediterranean-type food pattern is related to lower plasma concentrations of inflammatory markers and markers of endothelial dysfunction. ${ }^{434}$ These biomarkers are predictive of the future occurrence of type 2 diabetes. ${ }^{4546}$ In addition, a large cross sectional study nested in the nurses' health study found that increased adherence to a Mediterranean diet was associated with higher levels of adiponectin, ${ }^{47}$ and higher levels of adiponectin are associated with a reduced risk of diabetes.

\section{Limitations}

The number of new cases of diabetes was small, despite the follow-up of several thousand people for over four years. This small number of incident cases is a major drawback and can compromise the statistical power of our study. Nevertheless, our participants had high absolute levels of consumption of the typical food items of the Mediterranean diet, even among those participants classified as poorly compliant (score <3). For example, among those in the lowest category of adherence to the diet, the estimated mean daily absolute consumption (g/day) of olive oil (12), vegetables (308), fruits (176), cereals (77), and legumes (17) can be considered as healthy for the standards of nutritional epidemiological studies. This high

Table 2 | Incidence and relative risk of type 2 diabetes (confirmed cases) during follow-up according to adherence (Trichopoulou's score ${ }^{22}$ ) to Mediterranean food pattern at baseline

\begin{tabular}{llccc} 
& $\begin{array}{c}\text { No in } \\
\text { group }\end{array}$ & $\begin{array}{c}\text { Unadjusted } \\
\text { cumulative } \\
\text { incidence of type } 2 \\
\text { diabetes }(\%)\end{array}$ & $\begin{array}{c}\text { Incidence rate ratio* } \\
\text { adjusted for age and } \\
\text { sex }(95 \% \mathrm{Cl})\end{array}$ & $\begin{array}{c}\text { Multivariate adjusted } \\
\text { incidence rate ratio } \\
(95 \% \mathrm{Cl}) \dagger\end{array}$ \\
Low (score 0-2) & 2253 & 0.40 & 1 (reference) & 1 (reference) \\
\hline Moderate (score 3-6) & 9604 & 0.23 & $0.41(0.19$ to 0.87) & $0.40(0.18$ to 0.90) \\
\hline High (score 7-9) & 1523 & 0.13 & $0.17(0.04$ to 0.75) & $0.17(0.04$ to 0.72) \\
\hline
\end{tabular}

*Poisson regression model with robust standard errors.

†Adjusted for sex, age, years of university education (three categories), body mass index (continuous), family history of diabetes (two categories), hypertension at baseline (two categories), physical activity (three categories), hours/week sitting down (five categories), smoking (three categories), total energy intake (continuous). $\mathrm{P}=0.04$ for trend from likelihood ratio test when Trichopoulou's score was introduced as continuous variable in fully multivariate adjusted model. consumption of plant based foods in our cohort could be because our participants were from a Mediterranean country and were highly educated and health conscious. The small number of new cases observed in this study should therefore not be surprising. If the Mediterranean diet is actually protecting against diabetes, we would expecta low incidence in a young cohort (mean age is 37.8 years) with these characteristics. The low number of observed cases precluded assessment of the specific role of single dietary factors because we would have needed multiple adjustments for other dietary factors (in addition to the confounders already included in the model) and the statistical power to adjust for so many factors would have been low. The Mediterranean food pattern has the potential to minimise confounding by including nutritional confounders in the score and capturing effect modification among the nutritional variables. ${ }^{5}$

Diabetes might have been under-reported in our participants, despite their high educational level and easy access to medical care-half of them are health professionals. The proportions of participants aged over 65 years across increasing categories of adherence to the diet were $0.6 \%$ (score $<3$ ), $1.7 \%(3-6)$, and $3.5 \%$ $(>6)$. Therefore, older participants were more compliant with the diet. If selective under-reporting of diabetes was present among the older participants, this would provide an alternative non-causal explanation for our findings. We acknowledge this possibility, but the proportion of selective underdiagnosis of diabetes among older people is likely to be lower as they receive closer medical attention and routine medical care in Spain includes assessment of fasting glucose.

All our participants are university graduates and the generalisability of our findings to other groups with less education should be assumed only on biological grounds but not at all on "representativeness" of the general population. Also, the building of the diet score was based on sample specific median cut-off points, and our participants had high absolute levels of consumption of favourable foods and low absolute intakes of detrimental foods. Therefore, it will be difficult to compare our results with those of non-Mediterranean countries where levels of consumption of favourable foods in the general population are much lower. This is an additional limitation for external validity, but we selected the score proposed by Trichopoulou et al for the sake of comparability with previous studies. $^{822-2430-34}$

A potential caveat might be the quality of our nutritional assessment. Food frequency questionnaires are known to contain a certain degree of measurement error, which might affect results that depend on such questionnaires to assess diet and risk of chronic disease. Total energy intake was included as a covariate in the model to achieve the equivalent of an isocaloric diet and to reduce measurement error in the score. Measurement error, however, would probably have introduced non-differential misclassification, and the 


\section{WHAT IS ALREADY KNOWN ON THIS TOPIC}

A Mediterranean diet protects against coronary mortality and is inversely associated with metabolic syndrome and inflammatory markers

The diet was found to be inversely associated with the incidence of diabetes among patients who survived myocardial infarction

\section{WHAT THIS STUDY ADDS}

Higher adherence to a Mediterranean diet rich in olive oil, plant based foods (fruits, vegetables, and legumes), and fibre but low in meats was inversely associated with incidence of type 2 diabetes among initially healthy participants

implications for the results of this error would have been to bias the estimates towards the null.

A potential limitation, inherent to every observational design, is the possibility of residual confounding by unmeasured or unrecorded factors. Our major confounders, however, were sex and age. Additional adjustment for other factors made only negligible changes in the estimates, suggesting that residual confounding is unlikely.

\section{Conclusion}

Our prospective cohort study suggests that substantial protection against diabetes can be obtained with the traditional Mediterranean diet, rich in olive oil, vegetables, fruits, nuts, cereals, legumes, and fish but relatively low in meat and dairy products. The limited number of cases of diabetes and the possibility of under-reporting, however, requires that further larger cohorts and trials are needed to confirm our findings.

We are indebted to the participants of the SUN study for their continued cooperation and participation. We also thank others members of the SUN study group including: M Segui-Gomez, I de Irala, J A Martinez, A Marti, M Serrano-Martinez, F Guillen-Grima, E Toledo, R M Pajares, University of Navarra; M Delgado-Rodriguez, University of Jaen; J Llorca, University of Cantabria; E Smyth, University of Santiago de Compostela;

A Sanchez-Villegas, University of Las Palmas; I Marques-Lopes, University of Saragossa; A Alonso, University of Minnesota; and C N Lopez, Harvard University. We thank the members of the Department of Nutrition of the Harvard School of Public Health (A Ascherio, F B Hu, W C Willett) who helped us to design the SUN study.

Contributors: MAM-G and MB-R were responsible for study design, recruitment of participants, and statistical analyses and wrote the first draft of the manuscript; CF-A, ZV, SB, and AT were involved in data collection, technical support, and data management; JMN-C, FJB-G, JJB, and MAM-G applied the diagnosis criteria and comprised the medical panel for the adjudication of events. MAM-G obtained funding and is guarantor. Al authors provided suggestions during the different phases of the preparation of the manuscript and approved the final version submitted for publication.

Funding: Spanish Ministry of Health (Instituto de Salud Carlos III, Fondo de Investigaciones Sanitarias projects PI030678, PI040233, PI042241, PI050514, PI050976, PI070240; RD 06/0045) and the Navarra Regional Government (Department of Health, P141/2005) Competing interests: None declared.

Ethical approval: Institutional Review Board of the University of Navarra. Provenance and peer review: Not commissioned; externally peer reviewed.

1 Hossain P, Kawar B, El Nahas M. Obesity and diabetes in the developing world-a growing challenge. $N$ Engl J Med 2007;356:213-5.

2 International Diabetes Federation. Diabetes atlas. 3rd ed. Brussels: International Diabetes Federation, 2006.
3 Alberti KGMM, Zimmet P, Straw J. International diabetes federation: a consensus on type 2 diabetes prevention. Diabet Med 2007;24:451-63.

4 Hu FB, Manson JE, Stampfer MJ, Colditz G, Liu S, Solomon CG, Willett WC. Diet, lifestyle, and the risk of type 2 diabetes mellitus in women. N Engl J Med 2001;345:790-7.

5 Martinez-Gonzalez MA, Sánchez-Villegas A. The emerging role of Mediterranean diets in cardiovascular epidemiology: MUFA, olive oil, red wine or the whole pattern? Eur J Epidemiol 2004;19:9-13.

6 Estruch R, Martinez-Gonzalez MA, Corella D, Salas-Salvadó J, RuizGutiérrez V, Covas MI, et al. Effects of a Mediterranean-style diet on cardiovascular risk factors: a randomized trial. Ann Intern Med 2006;145:1-11.

7 Esposito K, Marfella R, Ciotola M, Di Palo C, Guigliano F, Giugliano G, et al. Effect of a Mediterranean-style diet on endothelial dysfunction and markers of vascular inflammation in the metabolic syndrome. IAMA 2004;292:1440-6.

8 Trichopoulou A, Costacou T, Bamia C, Trichopoulos D. Adherence to a Mediterranean diet and survival in a Greek population. N Engl J Med 2003;348:2599-608.

9 Knoops KT, de Groot LC, Kromhout D, Perrin AE, Moreiras-Varela O, Menotti A, et al. Mediterranean diet, lifestyle factors, and 10-year mortality in elderly European men and women. The HALE project. IAMA 2004;292:1433-9.

10 Salmeron J, Hu FB, Manson JE, Stampfer MJ, Colditz GA, Rimm EB, et al. Dietary fat intake and the risk of type 2 diabetes in women. Am J Clin Nutr 2001;73:1019-26.

11 Schulze MB, Schulz M, Heidemann C, Schienkiewitz A, Hoffmann K, Boeing $\mathrm{H}$. Fiber and magnesium intake and incidence of type 2 diabetes: a prospective study and meta-analysis. Arch Intern Med 2007;167:956-65.

12 Perez-Jimenez F, Alvarez de Cienfuegos G, Badimon L, Barja G, Battino M, Blanco A, et al. International conference on the healthy effect of virgin olive oil. Eur J Clin Invest 2005;35:421-4.

13 Garg A. High monounsaturated-fat diets for patients with diabetes mellitus: a meta-analysis. Am I Clin Nutr 1998;67(suppl):577-82S.

14 Rocca AS, LaGreca J, Kalitsky J, Brubaker PL. Monounsaturated fatty acid diets improve glycemic tolerance through increased secretion of glucagon-like peptide-1. Endocrinology 2001;142:1148-55.

15 Ros E. Dietary cis-monounsaturated fatty acids and metabolic control in type 2 diabetes. Am J Clin Nutr 2003;78(suppl):617-25S.

16 Paniagua JA, de la Sacristana AG, Sánchez E, Romero I, Vidal-Puig A, Berral FJ, et al. MUFA-rich diet improves postprandial glucose, lipid and GLP-1 responses in insulin-resistant subjects. J Am Coll Nutr 2007;26:434-44.

17 Willett WC. The Mediterranean diet: science and practice. Public Health Nutr 2006;9:105-10.

18 Mozaffarian D, Marfisi R, Levantesi G, Silletta MG, Tavazzi L, Tognoni G, et al. Incidence of new-onset diabetes and impaired fasting glucose in patients with recent myocardial infarction and the effect of clinical and lifestyle risk factors. Lancet 2007;370:667-75.

19 Martinez-Gonzalez MA, Sanchez-Villegas A, de Irala J, Marti A, Martinez JA. Mediterranean diet and stroke: objectives and design of the SUN project. Nutr Neurosci 2002;5:65-73.

20 Segui-Gomez M, de la Fuente C, Vazquez Z, de Irala J, Martinez-Gonzalez MA. Cohort profile: the "Seguimiento Universidad de Navarra" (SUN) study. Int J Epidemiol 2006;35:1417-22.

21 Martin-Moreno JM, Boyle P, Gorgojo L, Maisonneuve P, Fernandez-Rodriguez JC, Salvini S, et al. Development and validation of a food frequency questionnaire in Spain. Int J Epidemiol 1993;22:512-9.

22 Trichopoulou A, Kouris-Blazos A, Wahlquivist M, Gnardellis D, Lagiou P, Polychronopoulos E, et al. Diet and overall survival in elderly people. BMJ 1995;311:1457-60.

23 Bach A, Serra-Majem L, Carrasco JL, Roman B, Ngo J, Bertomeu I, et al. The use of indexes evaluating the adherence to the Mediterranean diet in epidemiological studies: a review. Public Health Nutr 2006;9:132-46

24 Tortosa A, Bes-Rastrollo M, Sanchez-Villegas A, Basterra-Gortari F), Nuñez-Cordoba JM, Martinez-Gonzalez MA. Mediterranean diet inversely associated with the incidence of metabolic syndrome: the SUN prospective cohort. Diabetes Care 2007;30:2957-9.

25 Bes-Rastrollo M, Perez Valdivieso JR, Sanchez-Villegas A, Alonso A Martinez- Gonzalez MA. Validacion del peso e indice de masa corporal auto-declarados de los participantes de una cohorte de graduados universitarios. Rev Esp Obes 2005;3:183-9 [in Spanish]

26 Martinez-Gonzalez MA, Lopez-Fontana C, Varo JJ, Sánchez-Villegas A Martinez JA. Validation of the Spanish version of the physical activity questionnaire used in the nurses' health study and health professionals' follow-up study. Public Health Nutr 2005;8:920-7.

27 Ainsworth BE, Haskell WL, Whitt MC, Irwin ML, Swartz AM, Strach SJ, et al. Compendium of physical activities: an update of activity codes and MET intensities. Med Sci Sports Exerc 2000;32:498-504.

28 Ramachandran A, Snehalatha C, Mary S, Mukesh B, Bhaskar AD, Vijay V. The Indian diabetes prevention programme shows that 
lifestyle modification and metformin prevent type 2 diabetes in Asian Indian subjects with impaired glucose tolerance (IDPP-1). Diabetologia 2006;49:289-97.

29 González-Clemente JM, Palma S, Arroyo J, Vilardell C, Caixàs A, Giménez-Palop 0 , et al. Is diabetes mellitus a coronary heart disease equivalent? Results of a meta-analysis of prospective studies. RevEsp Cardiol 2007;60:1167-76.

30 Trichopoulou A, Orfanos P, Norat T, Bueno-de-Mesquita B, Ocké MC, Peeters PH, et al. Modified Mediterranean diet and survival: EPICelderly prospective cohort study. BMJ 2005;330:991.

31 Mitrou PN, Kipnis V, Thiébaut AC, Reedy J, Subar AF, Wirfält E, et al. Mediterranean dietary pattern and prediction of all-cause mortality in a US population: results from the NIH-AARP diet and health study. Arch Intern Med 2007;167:2461-8.

32 Martinez-Gonzalez MA, Fernández-Jarne E, Serrano-Martinez M, Martí A, Martinez JA, Martín-Moreno JM. Mediterranean diet and reduction in the risk of a first acute myocardial infarction: an operational healthy dietary score. Eur J Nutr 2002;41:153-60.

33 Trichopoulou A, Bamia C, Trichopoulos D. Mediterranean diet and survival among patients with coronary heart disease in Greece. Arch Intern Med 2005;165:929-35.

34 Trichopoulou A, Bamia C, Norat T, Overvad K, Schmidt EB, Tjønneland A, et al. Modified Mediterranean diet and survival after myocardial infarction: the EPIC-Elderly study. Eur J Epidemiol 2007;22:871-81.

35 lestra J, Knoops K, Kromhout D, de Groot L, Grobbee D, van Staveren W. Lifestyle, Mediterranean diet and survival in European post-myocardial infarction patients. Eur J Cardiovasc Prev Rehabil 2006;13:894-900.

36 De Lorgeril M, Salen P, Martin JL, Monjaud I, Delaye J, Mamelle N. Mediterranean diet, traditional risk factors, and the rate of cardiovascular complications after myocardial infarction: final report of the Lyon diet heart study. Circulation 1999;99:779-85.

37 Schröder $\mathrm{H}$. Protective mechanisms of the Mediterranean diet in obesity and type 2 diabetes. J Nutr Biochem 2007;18:149-60.

38 Biesalski HK. Diabetes preventive components in the Mediterranean diet. Eur J Nutr 2004;43(suppl 1):126-30.
39 Pérez-Jiménez F, López-Miranda J, Mata P. Protective effect of dietary monounsaturated fat on arteriosclerosis: beyond cholesterol. Atherosclerosis 2002;163:385-98.

40 Perez-Martinez P, Lopez-Miranda J, Blanco-Colio L, Bellido C, JimenezY, Moreno JA, et al. The chronic intake of a Mediterranean diet enriched in virgin olive oil, decreases nuclear transcription factor kappaB activation in peripheral blood mononuclear cells from healthy men. Atherosclerosis 2007;194:e141-6.

41 Salas-Salvadó J, Garcia-Arellano A, Estruch R, Marquez-Sandoval F, Corella D, Fiol $M$, et al. Components of the mediterranean-type food pattern and serum inflammatory markers among patients at high risk for cardiovascular disease. Eur J Clin Nutr 2007 Apr 18 [Epub ahead of print].

42 Fitó M, Cladellas M, de la Torre R, Martí J, Muñoz D, Schröder H, et al. Anti-inflammatory effect of virgin olive oil in stable coronary disease patients: a randomized, crossover, controlled trial. Eur J Clin Nutr 2007;62:570-4.

43 Fung T, McCullough ML, Newby PK, Manson JE, Meigs JB, Rifai N, et al. Diet-quality scores and plasma concentrations of markers of inflammation and endothelial dysfunction. Am J Clin Nutr 2005;82:163-73.

44 Lopez-Garcia E, Schulze MB, Fung T, Meigs JB, Rifai N, Manson JE, et al. Major dietary patterns are related to plasma concentrations of markers of inflammation and endothelial dysfunction. Am J Clin Nutr 2004;80:1029-35.

45 Meigs JB, Hu FB, Rifai N, Manson JE. Biomarkers of endothelial dysfunction and risk of type 2 diabetes mellitus. JAMA 2004;291:1978-86.

46 Pradhan AD, Manson JE, Rifai N, Buring JE, Ridker PM. C-reactive protein, interleukin-6, and risk of developing type-2 diabetes. JAMA 2001;286:327-34.

47 Mantzoros CS, Williams CJ, Manson JE, Meigs JB, Hu FB. Adherence to the Mediterranean dietary pattern is positively associated with plasma adiponectin concentrations in diabetic women. Am J Clin Nutr 2006;84:328-35.

Accepted: 5 April 2008 